\section{Do tempo escolhido aos fins do sono: tempo de trabalho e renda básica no capitalismo tardio}

Recebido: 30.07.20 Aprovado: 18.09 .20
Josué Pereira da Silva*

Resumo: Partindo de estudos sobre a experiência de tempo no capitalismo tardio, o artigo concentra-se nos temas de tempo de trabalho e renda básica, vinculando-os às crises social e econômica que vivenciamos atualmente. Com base na análise desses dois temas relacionados, eu lido com o debate a respeito dos mesmos desde os anos 1970 até o momento presente. Argumento que a opção neoliberal por fundamentalismo de mercado levou ao crescimento da pobreza e da desigualdade social, situação agravada pela atual pandemia de Covid-19. Para combater as extremas pobreza e desigualdade social, concluo propondo a adoção de uma renda básica universal não apenas durante a pandemia, mas como estratégia permanente para proteger o tecido social dos efeitos destrutivos de uma expansão descontrolada da lógica de mercado sobre a vida das pessoas.

Palavras-chave: Capitalismo tardio. Tempo de trabalho. Renda básica.

\section{From chose time to the ends of sleep: \\ labor time and basic income in late capitalism.}

Abstract: Drawing on researches that diagnosis the experience of time in Late Capitalism the article focus on the themes of labor time and basic income, connecting them to the social and economic crises we live nowadays. Based on the analysis of these two related themes, I deal with the debate of these subjects from the 1970's to the present moment. I argue here that the neoliberal option for a market fundamentalism lead to an increase in poverty and social inequality, situation aggravated by the actual Covid-19 Pandemic. In order to fight poverty and extreme social inequality, I conclude by proposing the adoption of a universal basic income, not only as an emergency measure during the Pandemic, but as a permanent strategy to protect the social tissue from the destructive effects of an uncontrolled widespread market logic on peoples' life.

Key words: Late capitalism. Labor time. Basic income.

\section{Prólogo}

niciaremos a terceira década do século XXI tendo de lidar com uma pandemia que ceifa vidas e escancara para todos nós a dimensão e a gravidade da desigualdade social. Embora a desigualdade social seja uma condição permanente do capitalismo - que valoriza o sucesso individual -, ela é por isso mesmo sempre

\author{
* Professor de \\ sociologia no \\ Instituto de \\ Filosofia e Ciências \\ Humanas (IFCH), \\ da Universidade \\ Estadual de \\ Campinas (Unicamp), \\ Campinas, SP, \\ Brasil. Orcid: 0000- \\ 0002-8269-2930. \\ <josueps@unicamp. \\ br>.
}


escamoteada pelas elites políticas e econômicas do mundo inteiro. Mas, em momentos de crise como o que ora vivenciamos, ela se revela com toda força e ajuda a desmascarar o discurso neoliberal dominante para quem o mercado é capaz, por si só, de tudo resolver.

Em países como o Brasil, quase sempre na rabeira do debate internacional, as elites econômicas, políticas e midiáticas continuam a fazer vistas grossas para o que ocorreu na crise de 2008, quando o Estado - que aos olhos dos neoliberais só precisa ser mínimo quando se refere à proteção dos mais vulneráveis - foi chamado a socorrer o sistema financeiro, para que o mundo capitalista, que há muito se estende a todo o globo, não esboroasse. Com isso, o neoliberalismo ganhou fôlego, comprou - com recursos dos cidadãos, vale lembrar - uma sobrevida (Streeck, 2018). Mas até quando?

Agora, diante da pandemia de Covid-19 (coronavírus), a coisa se repete, em escala ampliada. A pandemia escancarou para quem quiser ver o quão daninha é a ausência de Estado, de políticas públicas sérias, sobretudo nos lugares onde a população mais necessita de um Estado de bem-estar, que de fato mereça esse nome. Mas a distribuição das riquezas, fruto da produção coletiva, está longe de entrar na agenda desses senhores.

Mesmo quando medidas emergenciais ainda que restritas e pontuais - como a dotação de duas ou três parcelas de seiscentos reais - voltadas à proteção dos setores mais vulneráveis da população se impõem, as velhas sereias de sempre insistem em repetir sua cantilena: "as medidas precisam ser provisórias". Imaginem, devem pensar, se a população se acostuma a receber dinheiro do Estado e, pior, se resolve querer mais?! Onde é que vamos parar?! Deixam claro, com isso, que preferem salvar empresas (CNPJs), ainda que para isso seja preciso sacrificar pessoas (CPFs). Quem sabe a morte em massa de parte desses últimos, principalmente dos mais pobres - predominantemente negros - e dos velhos dependentes da Previdência, não faz parte dos inconfessados cálculos dessas sereias neoliberais? Não devemos nos esquecer das sugestões de suspensão dos empregos e dos salários durante a crise; ou, na melhor das hipóteses, da sugestão de reduzir a duração do trabalho junto com a redução de salários. Tudo isso parece muito claro e, na verdade, nada tem de novo.

Mas não tenho aqui o intuito de fazer análise de conjuntura, mesmo porque, em meio a uma crise como a atual, qualquer análise desse tipo tende a se tornar obsoleta rapidamente. Não se sabe quando ela acabará nem como será o mundo pós- 
-pandemia. No entanto, dá para perceber no subtexto dos discursos dominantes - especialmente dos economistas oficiais e de certa imprensa que o replica - que pretendem continuar insistindo no "mais do mesmo", ou seja, salvar os interesses do mercado, financeiro principalmente, ainda que isso signifique o sacrifício dos setores mais vulneráveis da população.

Meu objetivo neste texto, conforme indica seu subtítulo, é discutir dois temas intimamente relacionados, que sempre estiveram no centro do conflito distributivo e têm sido, desde há muito tempo, de grande relevância para se entender a dinâmica do capitalismo, de ontem e de hoje: tempo de trabalho e transferência de renda.

Começo pelo debate em torno da redução do tempo de trabalho, tema pelo qual me interesso há muito tempo e que ocupou grande espaço no debate acadêmico e sociopolítico do último quartel do século XX, especialmente na Europa. Da análise desse tema, procuro então mostrar, em seguida, como do mesmo debate emergiu o outro tema do qual tratarei aqui: renda básica. Por fim, concluo fazendo algumas considerações sobre a relevância de ambos na atualidade.

\section{Tempo de trabalho}

Inicio este item com uma pequena digressão histórico-teórica sobre tempo de trabalho. Em termos teóricos, o tempo de trabalho está no centro das formulações de Marx a respeito da natureza e da dinâmica do capitalismo. A teoria do valor, desenvolvida por ele especialmente em $O$ capital, assenta-se em uma profunda análise da mercadoria como núcleo básico do sistema capitalista e nos mostra como a aparente igualdade embutida na relação de troca entre capitalistas e trabalhadores é apenas a forma aparente de uma assimetria de fundo, isto é, um fetiche que esconde a real relação de exploração da força de trabalho na qual se funda a dinâmica da economia capitalista (Marx, 1985).

Sua teoria da mais-valia, daí decorrente, revela como o lucro capitalista nada mais é do que a tradução da apropriação indevida do trabalho excedente realizado pelos trabalhadores, que são os verdadeiros produtores da riqueza social coletiva, apropriada privadamente pelos patrões, pelos capitalistas. Assim, explica Marx, qualquer jornada de trabalho é sempre formada por duas partes: uma primeira parte consiste no trabalho necessário à manutenção e reprodução da própria força de trabalho e de sua família: traduzida no que se conhece como salário; a outra parte é formada pelo trabalho excedente, isto é sobretrabalho, ou trabalho não pago, que Marx define como mais-valia e que é de onde sai o lucro capitalista. 
Esse constructo teórico, embora pareça abstrato aos não familiarizados com a teoria de Marx, esteve presente como substrato, como fundamento das formulações e demandas dos movimentos de trabalhadores em suas lutas pela redução da jornada de trabalho, ao menos desde a segunda metade do século XIX, quando a luta por uma jornada de trabalho de oito horas se transformou em uma das principais bandeiras de luta dos trabalhadores, em diversas partes do mundo. A propósito, vale lembrar que o próprio Marx dedicou um capítulo inteiro de 0 capital à análise teórica e histórica da jornada de trabalho (Marx, 1985: 187-238).

Assim, durante grande parte do século XIX e nas primeiras décadas do século XX, a redução do tempo de trabalho consistiu em uma das principais reivindicações dos movimentos de trabalhadores, traduzida principalmente na bandeira da jornada de trabalho de oito horas. Antes de ser conquistada e se consolidar em lei como jornada normal de trabalho em diversos países depois da Primeira Guerra Mundial, a jornada de trabalho de oito horas foi o motivo de uma longa história de luta dos trabalhadores contra os seus patrões; história essa permeada, muitas vezes, por momentos de luto, como no conhecido caso dos mártires de Chicago, em 1886 (Silva, 1996; Dal-Rosso, 1996).

A instituição, em diversos países, da jornada de trabalho de oito horas como jornada normal de trabalho a partir do fim da Primeira Guerra Mundial e consolidada principalmente nos anos posteriores à Segunda Guerra esteve muito associada à extensão da cidadania plena aos trabalhadores durante a vigência dos sistemas conhecidos como Estado de bem-estar social nos principais países da Europa e em alguns outros fora do contexto europeu (Silva, 2008).

No Brasil, vale lembrar, embora a luta dos trabalhadores pela jornada de trabalho de oito horas tenha se iniciado efetivamente no início de século XX, ela só se tornou lei em 1932, durante o governo de Getúlio Vargas; ainda assim, com aplicabilidade limitada em decorrência da falta de fiscalização (Silva, 1996; Gomes, 1988).

A chamada jornada normal de trabalho nos sistemas de bem-estar social, sobretudo dos países europeus, fazia parte de um conjunto maior que envolvia intervenção do Estado na economia, com a intenção de evitar suas oscilações cíclicas e também de garantir a estabilidade no emprego da força de trabalho. O bom funcionamento da economia e o pleno emprego da força de trabalho eram condições necessárias para o Estado construir uma sólida base de arrecadação de impostos, permitindoIhe atender às demandas da sociedade em termos de políticas públicas, entre as quais vale destacar os sistemas públicos educacional, de saúde e o seguro-desemprego (Espíng-Andersen, 1985; 1990; Baldwin, 1990). 
Essa era a base daquilo que ficou conhecido na época como compromisso fordista, que envolvia as participações de Estado, empresas e sindicatos, sob a égide do primeiro, na gestão da economia, de forma a manter o conflito de classes dentro de limites aceitáveis pelo capital ao mesmo tempo em que atendia as reivindicações básicas dos trabalhadores. Mas tudo isso dependia de certo equilíbrio na relação de força entre os três principais atores do jogo sociopolítico, além de autolimitação de cada um deles em busca de seus respectivos interesses.

Mas esse concerto começou a se desfazer logo que as empresas vislumbraram possibilidades de maiores lucros ao transferirem parte de suas plantas produtivas para países com legislação trabalhista mais frouxa e conivente com suas ambições de lucro fácil, em especial nos países com governos ditatoriais que reprimiam os movimentos sociais e operários em suas lutas por melhores condições de vida e trabalho.

O deslocamento de parte das plantas produtivas pelas então chamadas multinacionais para países que Ihes ofereciam condições de lucro mais favoráveis levou, em um primeiro momento, àquilo que inicialmente ficou conhecido como crise fiscal do Estado, produzindo assim as primeiras brechas no acordo até então vigente; a situação se agravou em seguida com o advento das crises do petróleo na década de 1970, abalando sobremaneira a economia capitalista (O'Connor, 1973).

As consequências mais evidentes de tais mudanças foram as altas taxas de desemprego com as quais os principais países da Europa passaram conviver desde então. Da metade da década de 1970 em diante começa-se, por conseguinte, a falar em crise do Estado de bem-estar social e não mais apenas de crise fiscal do Estado, como nos anos anteriores (Offe, 1984).

É nesse contexto também que o debate sobre redução do tempo de trabalho entra com muita força em cena. Inicialmente como medida para combater o desemprego, mas o seu alcance foi ampliado à medida que as rápidas transformações tecnológicas dos anos seguintes deixavam entrever a irrealidade das antigas proposições keynesianas de retorno ao pleno-emprego (Gorz, 1983; Offe, 1985; 1995).

À luz da revolução tecnológica poupadora de trabalho, o tema da redução do tempo de trabalho se tornou, portanto, uma bandeira bem mais ampla do que a de uma mera política de combate ao desemprego. É esse o contexto no qual emergem as proposições a respeito de modelos de sociedade com tempo de trabalho reduzido. Essa mesma situação contribuiu também para que textos heterodoxos como o Direito à preguiça, de Paul Lafargue, publicado inicialmente em 1880, fossem recuperados e trazidos para o centro das discussões (Lafargue, 1999). 
Em seu texto, Lafargue chamava a atenção para o equívoco dos trabalhadores de sua época que insistiam em competir com as máquinas, reivindicando mais emprego, mais trabalho, quando deviam, em sua opinião, lutar para trabalhar menos, para terem uma jornada de trabalho mais curta. Ele considerava, conforme argumenta no texto, que era perfeitamente plausível, considerando as condições de desenvolvimento técnico de então, uma jornada de trabalho de duas horas por dia.

Essa proposição de Lafargue é certamente uma fonte de inspiração, por exemplo, para o livro Travailler deux heures par jour, de 1977, de autoria do coletivo francês Adret, cujo título já deixa bem clara sua intenção de propor uma drástica redução do tempo de trabalho (Adret, 1977).

No mesmo ano de 1977, André Gorz publica - com o heterônimo Michel Bosquet - seu livro Écologie et liberté, no qual formula pela primeira vez a proposta de redução do tempo de trabalho como saída para as crises ecológica e de desemprego vivenciadas então pelos países europeus. Sobre as formulações de Gorz a respeito do tema, voltarei mais adiante; por ora, cabem mais algumas palavras sobre o projeto do coletivo Adret e seu referido livro.

O livro Travailler deux heures par jour parte da seguinte indagação: "por que quarenta horas?" (Adret, 1977: 9). Ao se referirem à jornada semanal de trabalho na França de então, seus autores combinam reflexão intelectual com narrativas de experiências de trabalhadores de diferentes categorias profissionais. Em sua pesquisa para a elaboração do livro, os autores indagam os trabalhadores sobre suas atividades, como cada um vivenciava o próprio trabalho em termos de remuneração, de horários ou de autossatisfação. A pesquisa, conforme mostram, indica que aqueles trabalhadores veem o trabalho que exercem bem distante de ser uma atividade prazerosa em qualquer dos sentidos acima, com destaque para sua insatisfação em relação à longa duração de um trabalho que eles consideram, por diferentes razões, alienante.

Por isso, os autores do livro lançam a seguinte assertiva, que de forma bem resumida faz um interessante diagnóstico do estado em que então se encontrava o debate sobre tempo de trabalho na França, embora o mesmo parecesse ocorrer em outras partes do mundo:

A sociedade atual tem um interesse vital em que a questão do trabalho não seja discutida. Para evitar todo debate, ela inculcou todos os tipos de bons princípios. A duração do trabalho, em particular, aparece determinada com o rigor de um dado natural. Diminuir o horário diário de oito horas, fixado há mais de 50 anos, 
parece tão inconcebível quanto reduzir o número de dias do ano, quanto mudar o número de horas do dia. O trabalho, em sua natureza e sua duração, repetitivo, entediante, consumidor de vida, aparece hoje como inevitável (Adret, 1977: 106-107)1.

E depois de concluírem que a redução da duração do trabalho não seria conquistada sem luta, propõem "uma estratégia política baseada em duas palavras de ordem: 'duas horas por dia' e 'igualdade das rendas'”. E ao considerar, ademais, que isso não seria conseguido sem mudanças profundas na sociedade, eles propõem que se exija de imediato para todos os trabalhadores uma "semana de 32 horas sem diminuição do salário mensal" (Adret, 1977: 178).

Vale observar aqui como, na formulação apresentada pelos autores, a reivindicação de redução do tempo de trabalho já se articulava com a exigência de manutenção da renda mensal. Assim, desde então e pelos anos seguintes, torna-se cada vez mais clara no debate a articulação entre os temas da redução tempo de trabalho e a da alocação de renda, seja para garantir a manutenção dos salários ou para que a transferência de renda à população ajudasse a viabilizar a redução geral e programada do tempo de trabalho.

No momento, porém, vou me limitar às proposições políticas em torno da redução do tempo de trabalho, deixando o tema da renda para ser tratado mais adiante.

Assim, desde a metade da década de 1970 até a virada para o novo século, o debate sobre a redução do tempo de trabalho se intensificou e o tema ganhou muita força nas agendas de discussões acadêmica e política em países como França, Alemanha e Itália, resultando daí um grande número de publicações, entre livros e artigos. Entre as diversas publicações resultantes desses debates, eu destaco um livro, que me parece exemplar. Trata-se de La révolution du temps choisi, de 1980, livro elaborado pelo coletivo Échanges et Projets (1980), com prefácio de Jacques Delors.

Esse livro contém uma proposta abrangente em termos de uma política de tempo para a sociedade francesa e também um bom diagnóstico de época, marcado, como sabemos, por um grande crescimento da produtividade do trabalho, que, por sua vez, recebia o impulso da então denominada "revolução microeletrônica" (Gorz, 1983). Mas, também sabemos, o crescimento da produtividade caminhava junto com o crescimento do desemprego em massa.

Em La révolution du temps choisi, os autores propunham como saída para o impasse entre crescimento da produtividade e desemprego em massa uma radical e
1. As traduções das citações em língua estrangeira ao longo deste texto são minhas. 
programada redução do tempo de trabalho, de forma que o aumento da produtividade do trabalho pudesse beneficiar a população como um todo e não apenas os detentores de capital, como estava acontecendo.

A proposição do coletivo Échanges et Projets contemplava, assim, um conjunto de ideias relacionadas ao debate que então se dava a respeito da redução do tempo de trabalho - incluindo suas diversas modalidades - e apostava em uma saída positiva para a crise de desemprego e uma solução para a metamorfose vivenciada pelo chamado mundo do trabalho por meio do que denominavam utopia do tempo escolhido.

Na conclusão do livro, seus autores sugeriam "uma política global de tempo", articulando-a com as três conhecidas palavras de ordem da Revolução Francesa de 1789: liberdade, igualdade e fraternidade.

Consideravam, enfim, que a proposição de uma sociedade de tempo escolhido contribuiria para reforçar as três mencionadas ideias-guia, tornando-se, assim, um projeto político ambicioso:

A política de tempo à qual nossa sociedade aspira é, de uma só vez, muito política e pouco política. Muito política porque ela exige dos governantes: fervor, intensidade, impulsão e convite à ação. Mas é pouco política no sentido de que constitui uma sorte de retorno radical à base, pois supõe um afastamento dos poderes e dos aparelhos burocráticos, e afirma, enfim, o primado das relações sociais em contraposição às estruturas (Échanges et Projets, 1980: 252).

2. A esse respeito, vale mencionar as duas seguintes coletâneas, como bons exemplos desse debate: Reiner Hoffmann \& Jean Lapeyyre, Le temps de travail en Europe: organisation et réduction; JeanPierre Chanteau \& Denis Clarc, Réduction du temps de travail: que faut-il croire?
Naquele momento, porém, o entendimento de que se vivia uma crise do trabalho parecia ainda se fundar em uma concepção de trabalho muito vinculada à ideia de trabalho manual característico das atividades da grande indústria de transformação e associado aos modelos de organização do trabalho de tipo taylorista e fordista, com intensa divisão de tarefas e produção em massa. Esse tipo de concepção pautou o debate sobre tempo de trabalho nas décadas seguintes, resultando na publicação de muitos livros, que atestavam a diversidade de abordagens a respeito do tema e ajudaram a tornar o debate mais complexo e intenso².

Na virada para o século XXI, entretanto, torna-se cada vez mais evidente que aquela concepção de trabalho, identificada ainda com o trabalho manual do operário fabril, parecia esboroar-se com a chamada emergência do imaterial associada à revolução digital (Rifkin, 2000; Gorz, 2005). 
E foi esse dado novo que, em grande medida, contribuiu para minar parte dos argumentos que sustentavam proposições de um modelo de sociedade fundada apenas numa política de redução do tempo de trabalho, a despeito de, naquela época, haver muitos autores que já propunham em adição a esse tipo de proposição argumentos em defesa de uma renda social; mas, nesse caso, a renda social era apenas um meio de facilitar a redução do tempo de trabalho sem uma correlata redução nos salários dos trabalhadores (Aznar, 1990; Gorz, 1991).

É nesse novo cenário de revolução tecnológica e digital que ganham sentido análises como a desenvolvida por Jonathan Crary em seu livro, de 2013, 24/7 - Capitalismo tardio e os fins do sono (Crary, 2016). Este último livro contém, da mesma forma que o livro anterior sobre "tempo escolhido", um bom diagnóstico de época, embora não partilhe daquele mesmo otimismo em relação à política de tempo; aliás, o livro de Crary, a meu ver, nada tem de otimista.

Em seu estudo, Jonathan Crary também faz um diagnóstico crítico (e um tanto sombrio), porém se refere a um momento mais recente - início da segunda década do século XXI - já se beneficiando por isso da experiência vivida durante o período dominado pelo neoliberalismo, incluindo aí também os avanços da revolução digital. A propósito, a expressão 24/7, que dá título ao livro, significa que, no capitalismo atual, estamos conectados o tempo todo, 24 horas por dia, sete dias por semana. Ou seja, aqui não há mais lugar para tempo livre; tampouco para tempo escolhido.

Nesse último contexto, a ideia de fins do sono, à qual o autor se refere no subtítulo do livro, tem em sua análise dois significados, a saber: primeiro que o sono é a última área da vida ainda não - mas em vias de ser - controlada pelo poder militar e colonizada pela lógica da mercadoria.

No primeiro significado apresentado por Crary, ele se refere, por exemplo, a estudos realizados sob o patrocínio da força aérea dos Estados Unidos, que busca preparar soldados capazes de combater durante muitos dias sem precisar dormir; e isso, não se deve esquecer, vale também para o modo de vida possibilitado pelas novas tecnologias que promovem a ideia de que as pessoas devem estar conectadas o tempo todo, enquanto desqualificam e desvalorizam aquelas que não se encaixam nesse padrão.

Em segundo lugar, e quiçá por isso mesmo, o sono é também, para Crary, a última trincheira de resistência à invasão das lógicas do poder e do mercado de que as pessoas dispõem; por ser um momento de suspensão de qualquer atividade, o sono se torna o espaço de onde, ele acredita, pode emergir a luta por emancipa-
3. Cabe aqui mencionar ainda outra discussão, paralela a essa, mas não exatamente igual, que trata do tempo livre, mas sem referência ao tema da distribuição de renda e que tem entre seus principais representantes Joffre Dumazedier (1988) e Roger Sue (1982; 1994). E, como contraponto crítico ao suposto otimismo em relação ao tempo livre, vale conferir os trabalhos de Daniel Mothé (1997; 1999). 
4. O sono e o sonho, como momentos de utopia e de possível lugar de resistência, aparecem também no livro do coletivo Adret, antes mencionado, e ainda no estudo de Jacques Rancière sobre $A$ noite dos proletários na primeira metade do século XIX (Rancière, 1988). ção, embora ele não deixe claro como isso se daria. É apenas nessa segunda perspectiva, portanto, que se pode vislumbrar algum resquício de utopia ${ }^{4}$.

Mas, para todos os efeitos, o importante na análise de Crary, a meu ver, é a diluição das fronteiras entre o tempo de trabalho e os outros tempos da vida das pessoas, convergindo assim para a percepção de que a exploração capitalista já não depende apenas da relação direta entre capital e trabalho, conforme entendiam as análises mais tradicionais do marxismo.

Ora, uma vez que nesse novo contexto do 24/7, dominado pelas grandes empresas detentoras de dados - os data brokers - toda interação social, conforme mostram diversos autores, contribui para a produção e/ou reprodução das relações capitalistas, todos nós, empregados ou não, queiramos ou não, também contribuímos direta ou indiretamente para a produção de "riquezas" (Rifkin, 2000).

E isso, embora Crary não diga nada a respeito, deixa entrever de forma clara que o tradicional vínculo entre trabalho assalariado e renda, fundado em uma economia de tempo baseada em uma suposta relação de equivalência, perdeu em grande medida seu fundamento; não mais se sustenta. E isso nos leva à abordagem do outro tema, o da renda básica.

\section{Renda básica}

É a partir desse novo contexto, portanto, que retorno ao tema da renda. Mas, para isso, também faço, assim como fiz com o tema da redução do tempo de trabalho, uma pequena digressão histórica e teórica.

Começo pela parte mais teórica. Se na discussão do tempo de trabalho recorri à teoria de Marx, agora, ao iniciar o tema da renda básica, eu me apoio em um modelo teórico elaborado a partir da obra de André Gorz. Em seu livro de 2003, 0 imaterial, Gorz desenvolve sua análise do capitalismo contemporâneo com base em um modelo formado pelas categorias conhecimento, valor e capital - aliás, as três palavras dão subtítulo ao livro - no qual conhecimento é a força produtiva principal (Gorz, 2005).

É possível, a meu ver, contrapor esse modelo a um modelo anterior, da época de Marx, que seria formado pelas categorias trabalho, valor e capital, no qual trabalho é a força produtiva principal. A comparação dos dois modelos indica que a diferença entre eles está justamente na substituição de trabalho por conhecimento. 
Em uma economia do conhecimento, afirma Gorz, a produtividade da maior parte das atividades não se presta a ser medida pelo tempo de trabalho, como no capitalismo clássico; além disso, muitas dessas atividades dependem de saberes práticos que também não se prestam a ser codificados e apropriados privadamente. Assim, parece claro que o principal evento por trás da mudança de um modelo a outro é a diluição do tempo de trabalho como critério para medir a produtividade; e isto afeta a teoria do valor, portanto, a base de cálculo das equivalências pelo capitalismo. E esta é, na análise de Gorz, a principal causa da crise do capitalismo. Ademais, para ele essa mudança contribui para colocar em dúvida o papel do trabalho assalariado como principal critério para a atribuição aos cidadãos de direito à renda (Gorz, 2004; 2005).

Mas a visão de Gorz a respeito do tema da transferência de renda, com o qual ele começou a se preocupar já em fins de 1980, tem suas próprias nuances e mudou ao longo do tempo. E essa mudança é uma chave interessante para se perceber como sua percepção da relação entre o tempo de trabalho e a atribuição de uma renda social mudou durante a segunda metade da década de 1990; e isso também tem a ver com seu intercâmbio intelectual com outros protagonistas dos mesmos debates (Silva, 2014: 63-83; Gollain, 2017).

A propósito, o próprio Gorz, quando começou a falar em renda social, a concebia como forma de financiar a redução do tempo de trabalho sem redução de salário; ou seja, a renda social parecia uma variável dependente da relação de trabalho. Mais precisamente, ele dizia, conforme atestam vários de seus escritos, que a renda social devia se desvincular do tempo de trabalho, mas não do trabalho, pura e simplesmente. Por isso mesmo, Gorz entendia que ela não estava em contradição com as propostas de redução do tempo de trabalho (Gorz, 1992).

Em seus escritos até 1996, Gorz sustentou essa posição com base no argumento de que o trabalho, ainda que em duração reduzida, constituía-se no direito político que todos tinham de participar da produção social. Ele entendia, então, que a atribuição de uma renda sem vínculo com o trabalho, conhecida no ambiente francês como alocação universal, era uma perspectiva liberal; a posição de esquerda por ele defendida, argumentava o autor à época, não devia abrir mão do vínculo entre renda e trabalho, mesmo que esse último fosse exercido em curta duração. E nisso ele não estava sozinho.

Guy Aznar, por exemplo, sociólogo francês que também participou intensamente do mesmo debate sobre redução do tempo de trabalho, chegou a cunhar a expressão "segundo cheque" para definir a renda social que ajudaria a financiar a redução do 
tempo de trabalho. Mas o "segundo cheque", em sua concepção, não devia ter como objetivo a liberação do trabalho, mas sim possibilitar que todos trabalhassem menos para poderem viver melhor. Por isso, ele argumentava que o "segundo cheque" não devia ser dirigido aos desempregados e aos que não queriam trabalhar, mas sim aos trabalhadores que tivessem disposição para reduzir sua jornada de trabalho, permitindo que assim outros também pudessem trabalhar (Aznar, 1981; 1990).

Gorz chegou, em certo momento, a utilizar de empréstimo, em seus escritos, a expressão "segundo cheque" de Aznar. Entretanto, a despeito das semelhanças entre eles no que refere ao vínculo entre trabalho e renda, a posição de Aznar não é necessariamente uma posição de esquerda, enquanto Gorz em todos os momentos fez questão de se definir como partidário de um socialismo democrático e ecológico, filiando-se, portanto, ao espectro político de esquerda.

Ele sintetiza de forma clara essa posição em seu livro, de 1991, Capitalisme, socialisme, écologie, no qual podemos encontrar em um dos capítulos sua ideia de "redução da duração do trabalho como contrato social", uma elaborada proposta política visando à redução programada do tempo de trabalho, bem próxima daquela encontrada no livro La révolution du temps choisi, do coletivo Échanges et Projets, sobre o qual escrevi acima (Gorz, 1991: 185-214; Silva, 2011: 174-184).

Mas a proposta de Gorz, já na época, incluía dois outros pilares, ainda ausentes na do livro de 1980, prefaciado por Jacques Delors: a atribuição de uma renda social, vinculada ao trabalho, mas não à sua duração; e o incentivo a atividades com valor social, mas sem valor de mercado, que ele define como atividades autônomas. Daí, a ideia de Gorz de uma sociedade de multiatividade (Gorz, 2004).

Em seu livro Misérias do presente, riqueza do possível, de 1997, porém, Gorz reviu sua posição a respeito do vínculo entre trabalho e renda, aproximando-se, desde então, dos defensores da alocação universal, ou renda básica de cidadania (Gorz, 2004). Ele se torna, portanto, como mostram seus escritos mais recentes, um dos principais defensores da atribuição de uma renda social desvinculada do trabalho (Gorz, 2005).

Entretanto, cabe, neste momento, falar um pouco de outro debate sobre transferência de renda que se desenvolveu paralelamente ao da redução do tempo de trabalho, mas de forma independente e, em grande medida, sem dialogar com o primeiro.

O debate mais recente sobre renda básica ganhou impulso na metade da década de 1980, quando um grupo de intelectuais e pesquisadores, principalmente europeus, 
decidiu lançar um movimento em prol da alocação de uma renda de base a todos os cidadãos. O tema não era novo, mas ele claramente ganhou vida nova a partir de 1986, beneficiando-se bastante do contexto de crise de desemprego que então atingia os principais países da Europa. E o marco mais nítido para impulsionar esse debate é, a meu ver, o texto "A capitalist road to communism", de 1986, escrito em coautoria por Robert Van der Veen e Philippe Van Parijs, e publicado pela revista Theory \& Society (Van der Veen e Van Parijs, 1986).

Desde então, o debate em torno desse tema cresceu e ganhou novos participantes, desembocando na criação, ainda na década 1980, da Rede Europeia de Renda Básica, mais tarde, em 2001, transformada em Rede Mundial de Renda Básica, com a mesma sigla de sua congênere anterior: Bien (Basic Income Earth Network). A substituição da palavra "European" pela palavra "Earth" permitiu, assim, que se mantivesse a mesma sigla em inglês (Suplicy, 2006: 56-61).

Essa última, por sua vez, lançou em 2006, 20 anos depois do texto que deslanchou o debate sobre renda básica, uma revista própria, intitulada Basic Income Studies. Só que dessa vez o texto principal do número inaugural dessa revista, "A capitalist road to global justice", assinado também por Robert J. Van der Veen e por Philippe Van Parijs, ao emular o título do artigo de 1986 que principiou o debate, trocou, como se pode ver, o nome comunismo pela expressão justiça global (Van der Veen e Van Parijs, 2006).

Sinal dos tempos? É possível. Nos 20 anos que transcorreram entre os dois textos, testemunhamos tanto o fim do comunismo no Leste Europeu como a emergência da chamada globalização, fenômenos que, tudo indica, não passaram despercebidos aos dois referidos autores. Não pretendo entrar aqui em semelhante discussão sobre a qual já existe uma vasta bibliografia 5 . Desde então, portanto, os debates se intensificaram e os experimentos de transferência de renda ao redor do mundo se multiplicaram.

Mas, enquanto o debate se enriqueceu pela diversidade de proposições a respeito das modalidades de transferência direta de renda, as políticas públicas adotadas pelos governos ao redor do mundo nesse campo restringiram-se, na grande maioria, a transferências condicionadas de renda, como é o caso do brasileiro Programa Bolsa Família, que talvez seja o maior no gênero pelo grande número de beneficiários por ele alcançado. Entretanto, é preciso lembrar que ele tem caráter limitado: tanto em relação ao valor monetário que distribui a cada família beneficiária, quanto às condicionalidades, que torna o programa uma política compensatória e limitada como política de cidadania (Silva, 2014).
5. Para quem tiver interesse especificamente nessa mudança de posição de um texto a outro, recomendo o estudo de Karina Vales Kappelli, que, em sua dissertação de mestrado, comparou os dois textos, assim como os conjuntos de textos dos dois dossiês publicados pelas revistas citadas Theory \& Society, de 1986; e Basic Income Studies, de 2006 (Cappelli, 2013). 
Em contraposição, a renda básica de cidadania deve ser, conforme a definição citada abaixo de um de seus principais teóricos e defensores, entendida como permanente e não se prende a nenhum tipo de condicionalidade:

Uma renda básica é uma renda paga por uma comunidade política a todos os seus membros individualmente, independentemente de sua situação financeira ou exigência de trabalho (Van Parijs, 2002: 195).

\section{Conclusão}

Vale retornar aqui ao tema do tempo de trabalho para rememorar a época em que os trabalhadores lutavam por uma jornada de trabalho de oito horas, cujo início situa-se no século XIX, mas tem raízes históricas ou mitológicas bem mais antigas (Langenfelt, 1954; Silva, 1996). Assim, a ideia de dividir as 24 horas do dia em três partes iguais - conhecido como $3 \times 8$ - oito horas de trabalho, oito horas de lazer e oito horas de sono, que foi pano de fundo da reivindicação pela jornada de trabalho de oito horas, transformou-se, ao longo do tempo, de um sonho, de um objetivo quase utópico, em um primeiro momento, em um quase pesadelo, pela ressignificação que the deu o capitalismo, ao se instituir em algumas empresas uma forma perversa de $3 \times 8$, na qual o trabalhador mudava de turno a cada semana, conforme testemunha um dos entrevistados pelo coletivo Adret, no livro já citado (Adret, 1977).

No primeiro $3 \times 8$, os trabalhadores tinham em mente uma situação de estabilidade temporal que Ihes permitia ter um horário fixo de sono, de repouso recuperador e até de sonho, como escreve Jacques Rancière em seu livro A noite dos proletários, no qual estuda os arquivos do sonho operário, ainda no século XIX (Rancière, 1988).

Diferentemente desse último, porém, o segundo $3 \times 8$ - dos turnos semanais mutantes - afetava negativamente o metabolismo e a psique dos trabalhadores, deixando-os constantemente estressados e Ihes provocando danos muitas vezes irreversíveis (Adret, 1977). Ainda aqui, entretanto, conforme também alegavam os trabalhadores entrevistados, os momentos de sono ainda Ihes permitiam sonhar com as benesses do que podiam ter fora do trabalho, nos poucos momentos de não trabalho, de lazer ou de sono.

Mas esse já não é mais o caso, quando olhamos para o estudo de Jonathan Crary, o 24/7, no qual o trabalho ocupa, disfarçadamente ou não, todas as 24 horas do dia não só dos trabalhadores formalmente empregados, mas também daqueles que vivem na informalidade ou mesmo na formalidade individualizada dos chamados PJs, ou CPFs transformados em supostos CNPJs (Crary, 2016). O estresse para eles é 
perene, constante, todos os dias. Assim, da antiga utopia dos $3 \times 8$ passamos para a distopia do $24 / 7$.

Nesse contexto bastante sombrio, as empresas detentores de dados cadastrais navegam de braçadas. Os bancos de dados se tornam a grande fonte de riqueza. E as empresas que os detêm não precisam pagar pelos dados que são seu cabedal, sua fonte de lucro. Em cada like de um seguidor de rede social, em cada "acessada" a uma página da internet, em cada disponibilização do próprio CPF durante uma inocente compra na farmácia, no supermercado, estamos alimentando, sem qualquer contrapartida, esses gigantes capitalistas. Pergunto-me se eles ao menos pagam (e se pagam, para quem) os impostos que deviam pagar.

Enquanto isso, a riqueza socialmente produzida não chega às grandes massas de população e a desigualdade social é cada vez maior. Em tal situação, por que não instituir de vez uma renda básica universal? Ela seria uma maneira de devolver um pouco do que se produz gratuitamente para essas grandes empresas - data brokers - que podem perfeitamente cumprir sua parte em um pacto social minimamente decente.

Como já adiantei no prólogo deste texto, a situação que vivemos atualmente, marcada por uma pandemia de consequências ainda imprevisíveis, repõe com muita força o tema da renda básica no centro da agenda dos debates sociopolíticos e econômicos.

A crise de 2008 já havia deixado clara a incapacidade das políticas neoliberais, centradas na hegemonia do mercado, salvarem a globalização capitalista sem a ajuda do Estado, que foi então chamado a socorrer o sistema financeiro a as grandes corporações empresariais, pilares do sistema.

Agora, com a pandemia de Covid-19, isso se tornou ainda mais evidente e escancarou as mazelas de um sistema que não só tolera, mas promove a desigualdade social por meio da destruição das antigas redes de proteção social, construídas com muita luta ao longo do tempo.

A ausência do Estado nos lugares onde mais dele se necessita mostra com clareza o lado perverso do chamado Estado mínimo, que nada tem de mínimo quando se trata de garantir os interesses dos ricos e dos poderosos. Um bom exemplo disso é a desconstrução programada ao longo dos anos da legislação trabalhista, representada pela antiga Consolidação das Leis do Trabalho (CLT), nos últimos governos, com suas contrarreformas neoliberais que só visavam aos interesses do chamado mercado, contribuindo para aumentar ainda mais a informalidade nas relações de trabalho e a vulnerabilidade de grandes camadas da população (Krein, 2018). 
Por outro lado, a crise atual mostrou também a importância dos poucos sistemas públicos de proteção da população, como o Sistema Único de Saúde (SUS), deixando claro para quem quiser ver que o direito à saúde de toda a população deve ser garantido pelo Estado e não pode ser tratado como objeto de relações mercantis.

Quem sabe isso contribua, por vias tortas e muito doloridas, para que se leve a sério a ideia de renda básica e se coloque em prática a lei de 2004, que institui a renda básica de cidadania a todas as pessoas (Silva, 2014: 101-118; 2019: 181-193). A ajuda financeira emergencial ora adotada é, nesse sentido, uma pista a indicar sua relevância. Resta saber se as forças políticas dominantes, incluindo aquelas à esquerda do espectro político, serão capazes de aprender a lição. É o que o espero.

\section{Referências}

ADRET. Travailler deux heures par jour. Paris: Les Éditions du Seuil, 1977.

AZNAR, Guy. Le travail, c'est fini: à plein temps, toute la vie, pour tout le monde, et c'est une bonne nouvelle. Paris: Pierre Belfond, 1990.

. Tout à mi-temps. Paris: Les Éditions du Seuil, 1981.

BALDWIN, Peter. The politics of social solidarity: class bases of the European Welfare State - 1875-1975. Cambridge (UK): Cambridge University Press, 1990.

BOSQUET, Michel (aliás André GORZ). Écologie et liberté. Paris: Éditions Galilée, 1977.

CAPPELLI, Karina Vales. Renda básica: entre comunismo e justiça social. Dissertação (Mestrado) - Instituto de Filosofia e Ciências Humanas (IFCH), Universidade Estadual de Campinas (Unicamp), Campinas, São Paulo, 2013.

CHANTEAU, Jean-Pierre; CLARC, Denis (Orgs.). Réduction du temps de travail: que faut-il croire? Paris: Syros, 1999.

CRARY, Jonathan. 24/7. Capitalismo tardio e os fins do sono. São Paulo: UBU, 2016.

DAL-ROSSO, Sadi. A jornada de trabalho na sociedade: o castigo de Prometeu. São Paulo: LTr Editora Ltda, 1996.

DUMAZEDIER, Joffre. Révolution culturelle du temps libre - 1968-1988. Paris: Méridiens Klinckieck, 1988.

ÉCHANGES ET PROJETS. La révolution du temps choisi. Paris: Albin Michel 1980. 
ESPING-ANDERSEN, Gosta. The three worlds of welfare capitalism. Princeton (NJ): Princeton University Press, 1990.

. Politics against markets: the social democratic road to power. Princeton (NJ): Princeton University Press, 1985.

GOMES, Angela de Castro. A invenção do trabalhismo. Rio de Janeiro: Vértice; luperj, 1988.

GOLLAIN, Françoise. André Gorz, pela incondicionalidade da renda. Caderno CRH, v. 30, n. 81, p. 497-505, 2017.

GORZ, André. O imaterial: conhecimento, valor e capital. São Paulo: Annablume, 2005.

. Misérias do presente, riqueza do possível. São Paulo: Annablume. 2004.

. On the difference between society and community, and why basic income cannot by itself confer full membership of either. In: VAN PARIJS, Philippe (Ed.). Arguing for basic income, p. 178-184. London: Verso, 1992.

. Capitalisme, socialisme, écologie: désorientations, orientations. Paris: Éditions Galilée, 1991.

. Les chemins du paradis. L'agonie du capital. Paris: Éditions Galilée, 1983.

HOFFMANN, Reiner; LAPEYRE, Jean (Orgs.). Le temps de travail en Europe: organisation et réduction. Paris: Syros, 1995.

KREIN, José Dari. O desmonte dos direitos, as novas configurações do trabalho e o esvaziamento da ação coletiva: consequências da reforma trabalhista. Tempo Social, v. 30, n. 1, p. 77-104, 2018.

LAFARGUE, Paul. O direito à preguiça. São Paulo: Editora Unesp; Hucitec, 1999.

LANGENFELT, Gösta. The historic origin of the eight hours day. Stockholm: Almqvist \& Wiksell, 1954.

MARX, Karl. O capital. São Paulo: Nova Cultural, 1985.

MOTHÉ, Daniel. Le temps libre contre la société. Paris: Desclée du Brouqer, 1999. . L'utopie du temps libre. Paris: Éditions Esprit, 1997.

O'CONNOR, James. The fiscal crisis of the State. New York: St. Martin Press, 1973.

OFFE, Claus. Full employment: asking the wrong question? Dissent, p. 77-81, Winter 1995. 
. Disorganized capitalism. Cambridge (MA): MIT Press, 1985.

. Contradictions of the welfare State. Cambridge (MA): MIT Press, 1984.

RANCIÈRE, Jacques. A noite dos proletários: arquivos do sonho operário. São Paulo: Companhia das Letras, 1988.

RIFKIN, Jeremy. The age of access: the new culture of hypercapitalism where all of life is a paid-for experience. New York: Penguin Putnam, 2000.

SILVA, Josué Pereira da. Sociologia crítica e a crise da esquerda. São Paulo: Intermeios, 2019. . Por que renda básica? São Paulo: Annablume, 2014. . André Gorz: trabalho e política. São Paulo: Annablume, 2011.

. Trabalho, cidadania e reconhecimento. São Paulo: Annablume, 2008.

- Três discursos, uma sentença: tempo de trabalho em São Paulo (19061932). São Paulo: Annablume, 1996.

STREECK, Wolfgang. Tempo comprado: a crise do capitalismo democrático. São Paulo: Boitempo, 2018.

SUE, Roger. Temps et ordre social. Paris: Presses Universtaires de France, 1994. 1982. . Vers une société du temps libre. Paris: Presses Universtaires de France,

SUPLICY, Eduardo Matarazzo. Renda básica de cidadania: a resposta dada pelo vento. Porto Alegre: L\&PM, 2006.

. Renda de cidadania: a saída é pela porta. São Paulo: Cortez Editora, 2002.

VAN DER VEEN, Robert J.; VAN PARIJS, Philippe. A capitalist road to communism. Theory \& Society, v. 15, n. 5, p. 635-655, 1986.

2006.

. A capitalist road to global justice. Basic Income Studies, v. 1, issue 1, p. 1-15,

VAN PARIJS, Philippe. Renda básica: renda mínima para o século XXI. In: SUPLICY, Eduardo Matarazzo. Renda de cidadania: a saída é pela porta, p. 194-230. São Paulo: Cortez Editora, 2002. 